\section{US faces danger in living off the fat of the land}

\section{Washington}

AN encyclopaedic, 712-page report* on the links between diet and disease received a mixed reception last week when it was released by the US Surgeon General, C. Everett Koop. Critics argued that the report, which took four years to prepare, breaks no new ground and fails to spell out specific nutritional guidelines. But the report's authors defended it as a comprehensive account of current knowledge from which policy recommendations and public programmes will later flow.

Koop described the report as a "landmark in Public Health Service efforts to improve the health of the American people" and compared it with the report on smoking, by Surgeon General Luther Terry in 1964, that triggered public recognition of the dangers of cigarette smoking.

In Nutrition and Health, the major villain is fat, particularly saturated fat (the kind, like butter, that remains solid at room temperature). Americans eat too much fat, according to Koop, and as a result suffer from increased rates of coronary heart disease, some types of cancer, strokes, diabetes and atherosclerosis. In Mediterranean countries, Japan and China, where much less fat is consumed, heart disease rates are much lower than those in the United States.

Coronary heart disease is now the United States' biggest killer. Of the 5,800 Americans who die each day, 35.7 per cent will succumb to heart disease, 22.4 per cent to cancer, 7.0 per cent to strokes, 1.8 per cent to diabetes and 1.1 per cent to atherosclerosis.

With twice as many calories per gram as carbohydrates and proteins, fat is also very fattening. Excessive consumption has led to an "extraordinarily high prevalence of obesity". One in four American adults are overweight and one in ten are severely overweight. Obesity brings increased risk for diabetes, hypertension, coronary artery disease and strokes, gallbladder disease and some types of cancer.

The surgeon general's advice is to switch from red meats and dairy products to lower-fat foods: vegetables, fruits, whole grains, fish and poultry. And he recommends an increase in consumption of complex carbohydrates and fibre grains and cereals, vegetables and fruits. Epidemiological and animal studies suggest they help to reduce the risks of cancer and diverticulosis, and may reduce blood cholesterol levels.

Attempts by Americans to improve their health by eating $\$ 1,500$ million per year of extra vitamins, minerals and other dietary supplements receives short shrift in the report. They are judged generally unnecessary, and excess consumption of them to be hazardous. Judgement is suspended on Omega-3 fatty acids from fish oils, an increasingly popular health-store product. Evidence that it reduces blood cholesterol levels and heart disease risk is considered too preliminary to recommend changes in intake.

Excess consumption of alcohol and salt are linked to increased mortality rates. Alcohol is seen as a factor in automobile and other accidents, and in suicides. These are the fourth ( 4.4 per cent $)$ and eighth (1.4 per cent) most frequent causes of death in the United States. The surgeon general recommends moderation - "no more than two drinks a day, if at all". Excess salt consumption is linked to high blood pressure and strokes. Average sodium intake for adults in the United States is 4-6 grams, four times the level judged safe and adequate.

To get across the report's message, Koop has called for a national campaign to change the American diet. But he stresses that the report is largely aimed at policymay be turned into action. Alun Anderson

*The Surgeon Generals' Report on Nutrition and Health (US Department of Health and Human Services, Public Health Department
Service.) makers. They will have to decide how it Vital boost for rocket fuel

\section{Las Vegas \& Boston}

LAST week, the Pacific Engineering and Production Company (PEPCON) unveiled plans for a new rocket fuel plant to replace the one destroyed in a gigantic explosion in Nevada nearly four months ago. The plant will manufacture ammonium perchlorate, a crystallized, oxidizing agent that constitutes more than two-thirds of the make-up of solid rocket fuel. The announcement has been eagerly awaited by the military, the National Aeronautics and Space Administration (NASA), Congress and the commercial space industry, because a new facility is vital if a shortage of rocket fuel is to be avoided next year.

The cause of the accident at the PEPCON plant in Henderson, Nevada, is still being investigated, but preliminary reports have attributed it to a gas leak under the plant. The explosion demolished the plant and halved the United States' production capacity of ammonium perchlorate. Two people were killed, hundreds were injured and millions of dollars worth of damage was done to the adjacent town. Local legislators are now trying to push through tough new laws governing the manufacture of hazardous chemicals.
At the national level, the PEPCON blast raised fears that an impending rocket fuel shortfall could cripple the US space launching capacity. The result has been a flurry of activity among US military, NASA, congressional subcommittees and the private companies involved.

To speed plans to increase production capacity, the Pentagon and NASA have pledged to buy a minimum of $\mathbf{1 0 0}$ million pounds (weight) of ammonium perchlorate over the next five years from both US producers. According to government estimates, 62 million pounds of ammonium perchlorate were being produced annually before the explosion. Maximum capacity is now under $\mathbf{4 0}$ million pounds and demand is expected to rise from approximately $\mathbf{5 8}$ million to 70 million pounds per year over the next few years. Although 24 million pounds is believed to be stockpiled, a serious shortfall may develop late next year.

Now that the location of a new facility has been established, PEPCON claims it can be back in production by February 1989, but others are doubtful. As NASA official Russell Bardos told reporters last month, "it will be 1991 before we can breathe easy again".

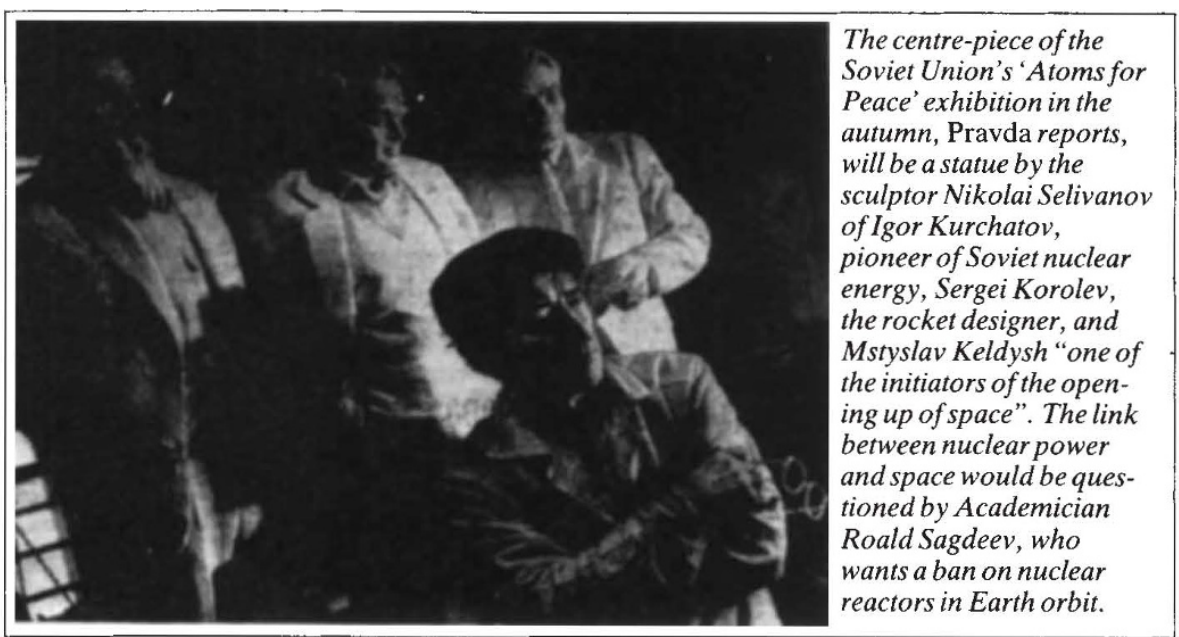

